\title{
EVALUACIÓN DE TRES SISTEMAS DE CULTIVO in vitro PARA LA MULTIPLICACIÓN DE MICROCORMOS DE GLADIOLO
}

\section{EVALUATION OF THREE in vitro CULTURE SYSTEMS FOR THE MULTIPLICATION OF GLADIOLUS MICROCORMS}

\section{J. Antonio Chávez-García, María Andrade-Rodríguez*, Porfirio Juárez-López, Oscar G. Villegas-Torres, Héctor Sotelo-Nava y Francisco Perdomo-Roldan}

Universidad Autónoma del Estado de Morelos. Cuernavaca, Morelos, México.

*Autor para correspondencia (maria.andrade@uaem.mx)

\section{RESUMEN}

En la industria ornamental, el gladiolo (Gladiolus spp) se encuentra dentro de las principales flores de corte a nivel mundial. La propagación es a través de cormos, con tasas de multiplicación bajas, lo que hace necesario el uso de técnicas de cultivo in vitro para obtener material vegetativo con características fisiológicas idénticas, uniformes y libres de enfermedades. Sin embargo, la investigación en multiplicación in vitro de gladiolo es escasa. El sistema de inmersión temporal (RITA) se usó con éxito para producir microcormos de gladiolo in vitro. A la fecha, el sistema de biorreactores de inmersión temporal (BIT) no se ha usado para producción de microcormos de gladiolo in vitro, lo cual implica sólo 25 $\%$ del costo de un sistema RITA. El objetivo fue evaluar tres sistemas de cultivo in vitro: medio semisólido, medio líquido en inmersión parcial y medio líquido en biorreactores de inmersión temporal (BIT), para la multiplicación de microcormos de gladiolo variedad "Ámsterdam". En el sistema BIT hubo un incremento de 91 \% en la multiplicación de microcormos en comparación con el sistema semisólido y de $100 \%$ en relación con el sistema de inmersión parcial. También el número de brotes fue mayor (41.3) en el sistema BIT que en el sistema de cultivo en medio semisólido y en el sistema de cultivo en medio líquido con inmersión parcial (5.8 y 6.5 brotes por explante). Estos resultados permitieron establecer el uso de biorreactores de inmersión temporal como mejor sistema para la multiplicación masiva de microcormos de gladiolo.

Palabras clave: Gladiolus spp, cultivo de tejidos vegetales, Sistemas de Inmersión Temporal, microcormos.

\section{SUMMARY}

In the ornamental industry, gladiolus (Gladiolus spp) is one of the main cut flowers worldwide. The propagation is through corms, with low multiplication rates, which makes it necessary to use in vitro techniques to obtain vegetative material with identical, uniform and disease-free physiological characteristics. However, the research about in vitro multiplication of gladiolus is scarce. The temporary immersion system (RITA) was used successfully to produce gladiolus microcorms in vitro. To date, the temporary immersion bioreactor system (BIT) has not been used for production of in vitro gladiolus microcorms, which represents only $25 \%$ of the cost of a RITA system. The objective was to evaluate three in vitro culture systems: semi-solid medium, liquid medium in partial immersion and liquid medium in temporary immersion bioreactors (BIT), for the multiplication of gladiolus microcorms of the variety "Ámsterdam". In the BIT system there was an increase of $91 \%$ in microcorms multiplication compared to the semisolid system and $100 \%$ in relation to the partial immersion system. The number of shoots was also higher (41.3) in the BIT system than in the semi-solid culture system and in the liquid culture system with partial immersion (5.8 and 6.5 shoots per explant). These results allowed the use of temporary immersion bioreactors to be established as the best system for the massive - multiplication of gladiolus microcorms.

Index words: Gladiolus spp, plant tissue culture, Temporary Immersion Systems, microcorms.

\section{INTRODUCCIÓN}

El gladiolo (Gladiolus spp) ocupa el octavo lugar a nivel mundial como cultivo para flor de corte, en tanto que en México ocupa el primer lugar de producción con 4,605.8 hectáreas; los estados productores son Estado de México, Puebla, Morelos, Michoacán, Guerrero, Veracruz y Oaxaca (SIAP, 2017). Su reproducción se basa en la multiplicación natural de cormos y microcormos. La tasa de multiplicación es lenta (se requieren dos ciclos de cultivo en campo) e insuficiente para abastecer la demanda comercial (Memon et al., 2016). El uso de la biotecnología vegetal con técnicas de cultivo de tejidos vegetales in vitro es aplicable en la industria ornamental, ideal para la multiplicación de materiales con potencial comercial (García-González et al., 2010), al obtener material vegetativo con características genéticas idénticas, uniformes y libres de enfermedades (Torabi-Giclou y Hajieghrari, 2008).

La aplicación comercial de la propagación in vitro con medio de cultivo semisólido puede ser limitada por la cantidad de material vegetal que se necesita para poner en marcha nuevas unidades de producción, por los altos costos de producción y por el tiempo requerido para la reproducción, debido a tasas de multiplicación bajas y pérdida de material por problemas de contaminación (Lyam et al., 2012); otra limitante es la escasez de automatización para la propagación masiva comercial (Berthouly y Etienne, 2005; Ruffoni y Savona, 2005; Mehrotra et al., 2007). Lo anterior limita la producción comercial de microcormos de gladiolo en México. 
El uso de medio de cultivo líquido en lugar de los medios semisólidos tiene beneficios en la tasa de crecimiento y multiplicación de los tejidos (Ascough y Fennell, 2004; Preil, 2005), reduce el trabajo del personal, facilita el contacto del explante con el medio de cultivo, permite la absorción de nutrientes y reguladores del crecimiento, además del escalamiento a través de la automatización de los procesos (Berthouly y Etienne, 2005; Mehrotra et al., 2007; Businge et al., 2017). Sin embargo, la exposición continua del material de propagación al medio líquido aumenta el riesgo de asfixia e hiperhidricidad (Berthouly y Etienne, 2005; Ruffoni et al., 2011; Lyam, 2012).

El sistema de inmersión temporal (SIT), al combinar los beneficios de la aireación del medio sólido y el contacto completo con medio líquido, ofrece una alternativa viable en la multiplicación in vitro (Escalona et al., 1999; Businge et al., 2017), ya que proporciona un entorno más natural para el cultivo in vitro de plantas. Los brotes cultivados se sumergen periódicamente en un medio líquido y luego se exponen a un entorno gaseoso, a través de un sistema semiautomático o totalmente automatizado (García-González et al., 2010; Georgiev et al., 2014). Como resultado se reducen los costos asociados con el manejo y la cosecha, facilitan la renovación del medio de cultivo, se reduce el área de estantería y la contaminación, mejoran la supervivencia en la aclimatación, e incrementan la eficiencia y la calidad de las plantas (Mehrotra et al., 2007; Lyam, 2012).

En gladiolo se ha estudiado la multiplicación in vitro en diferentes sistemas y condiciones (Prasad y Gupta, 2006; Ruffoni et al., 2011). Sin embargo, la investigación en multiplicación de microcormos in vitro es escasa (Memon et al., 2016). El sistema de inmersión temporal (RITA) se usó con éxito para producir microcormos, con diferente tasa de multiplicación por efecto del genotipo (Ruffoni et al., 2012). A la fecha, el sistema de biorreactores de inmersión temporal (BIT) (Escalona et al., 1999) no se ha usado para producción de microcormos de gladiolo in vitro, lo cual implica sólo $25 \%$ del costo de un sistema RITA. Por otro lado, la producción in vitro de microcormos de gladiolo es afectada significativamente por el genotipo (Ruffoni et al., 2011), por lo que es necesario determinar la respuesta de cada genotipo en particular. Con base en lo anterior, el objetivo de esta investigación fue evaluar tres sistemas de cultivo in vitro: medio semisólido, medio líquido en inmersión parcial y biorreactor de inmersión temporal, para la multiplicación de microcormos de gladiolo variedad "Ámsterdam".

\section{MATERIALES Y MÉTODOS}

La investigación se llevó a cabo en el Centro de Desarrollo Tecnológico de FIRA (Fideicomiso Instituido en
Relación a la Agricultura), Tezoyuca, Morelos, México. Los explantes fueron tomados de cormos de gladiolo, variedad "Ámsterdam" plantados en macetas $(15.24 \mathrm{~cm})$ con tepojal con una granulometría de $5 \mathrm{~mm}$, regados diariamente durante 25 días. El ápice del brote $(7 \mathrm{~mm}$ de ancho y $15 \mathrm{~mm}$ de alto) se extrajo de cormos previamente lavados.

\section{Desinfección de explantes}

Con base en ensayos preliminares se determinó la metodología de desinfección: los explantes se sumergieron en una solución de hipoclorito de sodio comercial (Cloralex®) al $3 \% \mathrm{v} / \mathrm{v}$ más $0.5 \mathrm{~g} \mathrm{~L}^{-1}$ de detergente roma en agua desmineralizada y se mantuvieron en agitación constante por cinco min. Posteriormente, en condiciones de asepsia, los ápices fueron colocados durante 18 minutos en una solución de hipoclorito de sodio comercial (Cloralex®) al $10 \%$ v/v con agua destilada estéril; posteriormente se enjuagaron tres veces con agua destilada estéril.

\section{Establecimiento in vitro}

Con base en ensayos preliminares se determinó el medio de cultivo y suplementos orgánicos a usar. Después de la desinfección, los ápices se cultivaron en medio MS (Murashige y Skoog, 1962) suplementado con tiamina, piridoxina, glicina, ácido nicotínico (1 $\left.\mathrm{mg} \mathrm{L}^{-1}\right), 120 \mathrm{mg} \mathrm{L}^{-1} \mathrm{de}$ inositol, $2 \mathrm{mg} \mathrm{L}^{-1}$ de 6-Benciladenina, $30 \mathrm{~g}$ de sacarosa, 6.5 $\mathrm{g} \mathrm{L}^{-1}$ de agar (Merck $\AA$ ), con un pH ajustado a 5.7 ( $\mathrm{pH}$ metro Hanna $\left.{ }^{\circledR}\right)$. El medio se esterilizó durante 18 min en autoclave (Equipos médicos especiales ARA $®$ ) a $1.2 \mathrm{~kg} \mathrm{~cm}^{-2}$ y 120 ${ }^{\circ} \mathrm{C}$. En cada tubo de cultivo que contenía $10 \mathrm{~mL}$ de medio se estableció un ápice. Los cultivos se incubaron a $24 \pm 2{ }^{\circ} \mathrm{C}$, con fotoperiodo de 16 h luz (1800 lux) y 8 horas de oscuridad. Después de dos periodos de cultivo de 30 días cada uno, en el mismo medio de cultivo, se obtuvo cada propágulo (grupos de brotes menores de $10 \mathrm{~mm}$ de longitud).

\section{Sistemas de cultivo in vitro}

Para evaluar los tres sistemas de cultivo in vitro se usaron grupos de brotes (menores de $10 \mathrm{~mm}$ de longitud) obtenidos del establecimiento descrito anteriormente. El medio de cultivo utilizado fue el MS (Murashige y Skoog, 1962) suplementado con tiamina, piridoxina, glicina, ácido nicotínico (1 $\left.\mathrm{mg} \mathrm{L}^{-1}\right), 120 \mathrm{mg} \mathrm{L}^{-1}$ de inositol, $1.0 \mathrm{mg} \mathrm{L}^{-1} \mathrm{de}$ ácido 3-Indolbutírico (AIB), $0.6 \mathrm{mg} \mathrm{L}^{-1}$ de 2-isopentil adenina (2iP) (Ruffoni et al., 2012), $80 \mathrm{~g}$ de sacarosa y pH de 5.7. El medio se esterilizó en autoclave a $1.2 \mathrm{~kg} \mathrm{~cm}^{-2}$ y $120{ }^{\circ} \mathrm{C}$ durante $18 \mathrm{~min}$. Para todos los tratamientos se utilizaron frascos de vidrio tipo conserveros de $980 \mathrm{~mL}$.

Los brotes se cultivaron en tres sistemas: medio semisólido con $6.5 \mathrm{~g} \mathrm{~L}^{-1}$ de agar, inmersión parcial de acuerdo 
a Escalona et al. (1999) (5 mm de la base del brote se sumergió en medio líquido), e inmersión temporal utilizando el Biorreactor de Inmersión Temporal (BITß) (Escalona et al., 1999). En éstos se utilizaron 60, 30 y $250 \mathrm{~mL}$ de medio de cultivo, respectivamente. En cada sistema se utilizaron cinco brotes por frasco. En el caso del BIT se usaron 3 min de inmersión con una frecuencia de $4 \mathrm{~h}$. El diseño experimental utilizado fue completamente al azar con cuatro repeticiones por tratamiento.

Al igual que el establecimiento in vitro, los cultivos se mantuvieron a una temperatura de $24 \pm 2{ }^{\circ} \mathrm{C}$, con un fotoperiodo de $16 \mathrm{~h}$ luz (1800 lux) y 8 horas de oscuridad, usando lámparas de luz blanca.

La evaluación de los tres sistemas de cultivo se hizo después de 110 días de incubación (sin subcultivos). Las variables evaluadas fueron número de brotes por explante, longitud $(\mathrm{mm})$ de brote, número de raíces, longitud $(\mathrm{mm})$ de raíz y número, diámetro y biomasa de microcormos. Las variables de longitud y diámetro se midieron con vernier digital marca Truper®.

\section{Análisis de datos}

Los datos de cada variable se estudiaron mediante análisis de varianza (ANOVA) y se realizó la prueba de comparación de medias (Tukey), mediante el paquete estadístico SAS versión 9.0 (SAS Institute, 2002).

\section{RESULTADOS Y DISCUSIÓN}

Los resultados del análisis de varianza en las siete variables evaluadas indicaron diferencias altamente significativas $(P \leq 0.05)$ entre los sistemas de cultivo in vitro (análisis no mostrado en cuadro).

Los resultados en cada sistema se muestran en el Cuadro 1. El sistema de inmersión temporal BIT claramente generó 80 \% más brotes que los otros dos sistemas. El sistema con medio semisólido produjo una cantidad de brotes similar al sistema de inmersión parcial. De igual modo, la longitud de brotes fue mayor en el sistema BIT, cuya diferencia fue mayor de 19 \% con relación al sistema semisólido y 68 \% con respecto al sistema de inmersión parcial, lo que indica mayor producción de biomasa en los cultivos de sistema BIT. Los brotes con menor longitud fueron los obtenidos en el sistema de inmersión parcial.

Aunque se reporta que los medios líquidos pueden aumentar la tasa de proliferación de brotes, además de permitir la automatización (Prasad y Gupta, 2006), en esta investigación se observó que el uso de medio líquido con inmersión parcial generó resultados similares a los obtenidos con medio semisólido.

En la comparación de los sistemas de cultivo sólidos y líquidos, los sistemas de biorreactores de inmersión temporal (BIT) han demostrado ofrecer beneficios tecnológicos y cuantitativos, como mayor tasa de proliferación, tal como ocurrió en esta investigación y como se reporta para cultivares de Eucalyptus Birch y Fir (Businge et al., 2017) Esto coincide también con lo reportado por Escalona et al. (1999) para piña (A. comosus L.), en donde se observó que los explantes cultivados en el sistema de inmersión temporal tuvieron la mayor tasa de multiplicación, misma que aumentó en 3.5 y 4.8 respecto a la obtenida en medio líquido y sistemas convencionales de soporte sólido, respectivamente. Resultados similares se obtuvieron en Paeonias sp. (Lezcano et al., 2010).

Además de producción de brotes se logró la formación y crecimiento de raíces. Ésta se vio favorecida en el sistema BIT pues se tuvieron cuatro veces más raíces que en el sistema semisólido, caso contrario ocurrió en el sistema de inmersión parcial en donde no hubo formación de raíces (Cuadro 1). La longitud de raíces fue inversamente proporcional al número de éstas, ya que las raíces más largas fueron las del menor número de brotes obtenidos en el sistema con medio semisólido.

Cuadro 1. Características de brotes y microcormos de gladiolo variedad Ámsterdam en tres sistemas de cultivo in vitro.

\begin{tabular}{lccccccc}
\hline $\begin{array}{l}\text { Sistema de } \\
\text { cultivo }\end{array}$ & Brotes (Núm.) & $\begin{array}{c}\text { Longitud de } \\
\text { brote }(\mathrm{mm})\end{array}$ & $\begin{array}{c}\text { Raíces } \\
(\text { Núm.) }\end{array}$ & $\begin{array}{c}\text { Longitud de } \\
\text { raíz }(\mathrm{mm})\end{array}$ & $\begin{array}{c}\text { Microcormos } \\
(\text { Núm. })\end{array}$ & $\begin{array}{c}\text { Diámetro de } \\
\text { microcormo } \\
(\mathrm{mm})\end{array}$ & $\begin{array}{c}\text { Biomasa de } \\
\text { microcormo } \\
(\mathrm{g})\end{array}$ \\
\hline MSS & $5.75 \mathrm{~b}$ & $204.2 \mathrm{~b}$ & $6.75 \mathrm{~b}$ & $74.95 \mathrm{a}$ & $3.00 \mathrm{~b}$ & $6.20 \mathrm{a}$ & $0.252 \mathrm{a}$ \\
MLIP & $6.50 \mathrm{~b}$ & $80.0 \mathrm{~b}$ & $0.00 \mathrm{c}$ & $0.00 \mathrm{c}$ & $0.00 \mathrm{~b}$ & $0.00 \mathrm{~b}$ & $0.000 \mathrm{c}$ \\
BIT & $41.25 \mathrm{a}$ & $252.5 \mathrm{a}$ & $29.50 \mathrm{a}$ & $40.00 \mathrm{~b}$ & $34.75 \mathrm{a}$ & $6.57 \mathrm{a}$ & $0.352 \mathrm{a}$ \\
DSH (0.05) & 11.40 & 45.83 & 7.61 & 7.37 & 9.18 & 1.38 & 0.116 \\
\hline
\end{tabular}

Medias con letras iguales no son estadísticamente diferentes (Tukey, 0.05), DSH: Diferencia significativa honesta. MSS: medio semisólido, MLIP. medio líquido en inmersión parcial, BIT: medio líquido en biorreactores de inmersión temporal. 
Con respecto al número de microcormos, el sistema BIT incrementó la producción en 11.6 veces en comparación con el sistema de cultivo en medio semisólido y 34.8 veces más que en el sistema de inmersión parcial, en el cual no se formaron microcormos (Cuadro 1). Estos resultados concuerdan con lo reportado por Ruffoni et al. (2012), quienes evaluaron la proliferación y el diámetro de microcormos de gladiolo después de 90 días de cultivo. Los mismos autores señalan que las plantas crecieron más rápido en el sistema de inmersión temporal RITA® que en medio sólido; además mencionan que no fue necesario hacer subcultivos del material, lo cual permitió cosechar los microcormos de gladiolo directamente del biorreactor. También hay similitud con lo observado en la producción de microtubérculos de papa (Solanum tuberosum), en la cual se tuvo mayor cantidad de tubérculos al usar la inmersión temporal que cuando se usó medio semisólido (Jiménez et al., 1999).

El diámetro de los microcormos (Cuadro 1) fue similar en el sistema de cultivo en medio semisólido y en el sistema $\mathrm{BIT}$, en los cuales se tuvo un diámetro de $6.4 \mathrm{~mm}$; de igual manera, la biomasa de los microcormos obtenidos en ambos sistemas de cultivo fue similar. Con relación al tamaño de las estructuras de multiplicación, Lezcano et al. (2010) observaron mayor tamaño de brote principal en Paeonias $\mathrm{sp}$. al usar el sistema de inmersión temporal que en medio semisólido y en medio líquido estático. Los resultados de la presente investigación contradicen lo reportado por Jiménez et al. (1999), quienes indicaron que el sistema de inmersión temporal aumentó el tamaño y biomasa de tubérculos de papa.

El mejor sistema para la multiplicación de brotes y microcormos de gladiolo in vitro fue el sistema de biorreactor de inmersión temporal (BIT) (Cuadro 1). Lo anterior se explica porque en este sistema, de manera periódica, los explantes tuvieron contacto con los componentes del medio de cultivo por todos lados durante $3 \mathrm{~min}$, facilitando la absorción de nutrientes y reguladores del crecimiento (Berthouly y Etienne, 2005; Mehrotra et al., 2007; Businge et al., 2017); además, este sistema permite que el medio de cultivo y los explantes reciban oxigenación de manera periódica (Escalona et al., 1999; Businge et al., 2017). Ambas situaciones repercutieron en mayor tasa de multiplicación de brotes y microcormos. Los resultados obtenidos en esta investigación serán de utilidad para la propagación masiva de gladiolo con material de calidad física y sanitaria, para solucionar la demanda de cormos comerciales en la producción de flor de corte.

En conclusión, la mayor eficiencia de multiplicación de brotes y microcormos de gladiolo se logra en el cultivo en medio líquido en biorreactores de inmersión temporal (BIT), donde se pueden recolectar con facilidad.

\section{BIBLIOGRAFIA}

Ascough G. D. and C. W. Fennell (2004) The regulation of plant growth and development in liquid culture. South African Journal of Botany 70:181-190.

Berthouly M. and H. Etienne (2005) Temporary immersion system: a new concept for use liquid medium in mass propagation. In: A. K. Hvoslef-Eide and W. Preil (Eds.). Liquid culture systems for in vitro plant propagation. Springer. Dordrecht, Netherlands. pp: 165-203.

Businge E., A. Trifonova, C. Schneider, P. Rödel and U. Egertsdotter (2017) Evaluation of a new temporary immersion bioreactor system for micropropagation of cultivars of eucalyptus, birch and fir. Forests 8: 196

Escalona M., J. C. Lorenzo, B. González, M. Daquinta, J. L. González D. and C. G. Borroto (1999) Pineapple (Ananas comosus L. Merr) micropropagation in temporary immersion systems. Plant Cell Reports 18:743-748.

García-Gonzáles R., K. Quiroz, B. Carrasco and P. Caligari (2010) Plant tissue culture: Current status, opportunities and challenges. Ciencia e Investigación Agraria 37:5-30.

Georgiev V., A. Schumann, A. Pavlov and T. Bley (2014) Temporary immersion systems in plant biotechnology. Engineering in Life Sciences 14:607-621.

Jiménez E., N. Pérez, M. de Feria, R. Barbón, A. Capote, M. Chávez and E. Quiala (1999) Improved production of potato microtubers in a temporary immersion system. Plant Cell Tissue and Organ Culture 59:19-23.

Lezcano Y., M. Escalona, M. Daquinta (2010) Multiplicación in vitro de Paeonias sp. variedad 'SeSu' en Sistemas de Inmersión Temporal. Biotecnología Vegetal 10:169-175.

Lyam P. T., M. L. Musa, Z. O. Jamaleddine and U. A. Okere (2012) The potential of temporary immersion bioreactors (TIBS) in meeting crop production demand in Nigeria. Journal of Biology and Life Science 3:66-86

Mehrotra S., M. K. Goel, A. K. Kukreja and B. N. Mishra (2007) Efficiency of liquid culture systems over conventional micropropagation. African Journal of Biotechnology 6:1484-1492.

Memon N. U. N., N. A. Wahocho, T. F. Miano and M. H. Leghari (2016) Propagation of Gladiolus corms and cormels: A review. African Journal of Biotechnology 15:1699-1710.

Murashige T. and F. Skoog (1962) A revised medium for rapid growth and bioassays with tobacco cultures. Physiology Plantarum 15:473-497

Prasad V. S. S. and S. D. Gupta (2006) In vitro shoot regeneration of gladiolus in semi-solid agar versus liquid cultures with support systems. Plant Cell Tissue and Organ Culture 87:263-271.

Preil W. (2005) General introduction: a personal reflection on the use of liquid media for in vitro culture. In: A. K. Hvoslef-Eide and W. Preil (Eds.). Liquid Culture Systems for in vitro Plant Propagation. Springer. Dordrecht, Holanda. pp: 1-18.

Ruffoni B. and M. Savona (2005) The Temporary Immersion System (T.I.S.) for the Improvement of Micropropagatión of Ornamental Plants. Acta Horticulturae 683:445-449.

Ruffoni B., M. Pamato and M. Brea (2011) Improvement of the propagation of Gladiolus hybrids selected for extra-season mediterranean production. Acta Horticulturae 886:219-224.

Ruffoni B., M. Savona and S. Barberini (2012) Biotechnological support for the development of new gladiolus hybrids. Floriculture and Ornamental Biotechnology 1:45-52.

SAS Institute (2002) SAS/STAT Version 9.00. User's Guide. SAS Institute Inc. Cary, NC, USA. 4424 p.

SIAP, Servicio de Información Agroalimentaria y Pesquera (2017) Estadística de la Producción Agrícola de 2017. http://infosiap.siap.gob. $\mathrm{mx} / \mathrm{gobmx} /$ datosAbiertos.php.

Torabi-Giglou M. and B. Hajieghrari (2008) In vitro study on regeneration of Gladiolus grandiflorus corm calli as affected by plant growth regulators. Pakistan Journal Biological Sciences 11:1147-1151. 